\title{
PRESERVAÇÃO DA RIQUEZA SOCIOEMOCIONAL E A PROFISSIONALIZAÇÃO EM EMPRESAS FAMILIARES'
}

\section{Preservation of socioemotional wealth and professionalization in family businesses}

\begin{abstract}
Alice Carolina Ames
E-mail: aliceames@hotmail.com

Mestre em Ciências Contábeis pela Universidade Regional de Blumenau; doutoranda em Ciências Contábeis e Administração pela Regional de Blumenau; Bolsista CAPES na Universidade Regional de Blumenau.

Endereço para contato: Rua Antônio da Veiga, 140, 8903-0003, Itoupava Seca, Blumenau, Santa Catarina, Brasil. https://orcid.org/0000-0002-8287-8831

Jessica Giovana Nolli
\end{abstract}

E-mail: jessicanolli@hotmail.com

Mestre em Ciências Contábeis pela Universidade Regional de Blumenau; Especialista em Gestão Societária pela Universidade para o Desenvolvimento do Alto Vale do Itajaí. https://orcid.org/0000-0001-7031-3908

Franciele Beck

E-mail: beck.franciele@gmail.com

Doutora em Controladoria e Contabilidade pela Universidade de São Paulo; Mestre em Ciências

Contábeis pela Universidade Regional de Blumenau; Professora no Departamento de Ciências Contábeis e no Programa de Pós-Graduação de Ciências Contábeis da Universidade Regional de

Blumenau.

https://orcid.org/0000-0001-7390-5933

Daniel Magalhães Mucci

E-mail: danielmmucci@gmail.com

Ph.D. em Economia Aplicada pela Universidade da Antuérpia; Doutor em Controladoria e Contabilidade pela Universidade de São Paulo; Professor no Departamento de Contabilidade e Atuária da Universidade de São Paulo. https://orcid.org/0000-0002-0658-1470

Artigo recebido em 21 de fevereiro de 2020. Aceito em 28 de outubro de 2020.

\footnotetext{
' Conforme Portaria N ${ }^{\circ}$ 206, de 4 de setembro de 2018, o presente trabalho foi realizado com apoio da Coordenação de Aperfeiçoamento de Pessoal de Nível Superior - Brasil (CAPES) - Código de Financiamento 001.
} 


\section{Resumo}

Empresas familiares dominam os negócios em grande parte das economias mundiais exercendo influência sobre o ambiente econômico-social. Este estudo objetiva investigar como a riqueza socioemocional impacta no processo de profissionalização em uma empresa familiar. A pesquisa caracteriza-se como exploratório, estudo de caso qualitativo realizado em uma empresa localizada em Santa Catarina com 50 anos de história, sendo uma empresa S.A de capital fechado de grande porte. As entrevistas foram analisadas pela abordagem da análise do discurso. Os resultados da pesquisa sugerem que a riqueza socioemocional influenciou a profissionalização no sentido de preservar os valores da família, dado que a profissionalização ocorreu com o intuito de manutenção e sobrevivência do negócio. Além disso, a contratação de profissionais não familiares permitiu diferentes percepções para a tomada de decisões, agregando valor à tomada de decisão. A contribuição teórica do estudo consiste na discussão da riqueza socioemocional e da profissionalização, no que tange ao envolvimento da família na organização e a participação de profissionais não familiares na gestão do negócio, levando em consideração que a riqueza socioemocional reforça a profissionalização da empresa familiar. Esse estudo amplia o debate acerca da profissionalização em empresas familiares sugerindo que esse processo não concorre com a manutenção da riqueza socioemocional.

Palavras chave: Riqueza socioemocional. Profissionalização. Empresa familiar.

\section{Abstract}

Family businesses dominate business in most of the world's economies, influencing the socialeconomic environment. This study aims to investigate how socioemotional wealth impacts the professionalization process in a family business. The research is characterized as exploratory, a qualitative case study carried out in a company located in Santa Catarina with 50 years of history, being a large-scale, privately-held company. The interviews were analyzed using the discourse analysis approach. The results of the research suggest that socioemotional wealth influenced professionalization to preserve family values, given that professionalization occurred to maintain and survive the business. Also, the hiring of non-family professionals allowed different perceptions for decision making, adding value to decision making. The theoretical contribution of the study consists of the discussion of socioemotional wealth and professionalization, about the involvement of the family in the organization, and the participation of non-family professionals in the management of the business, taking into account that the socioemotional wealth reinforces the professionalization of the family business. This study broadens the debate about professionalization in family businesses, suggesting that this process does not compete with the maintenance of socioemotional wealth. Keywords: Socioemotional Wealth. Professionalization. Family Business.

\section{INTRODUÇÃO}

Embora existam inúmeras definições e classificações para o envolvimento da família na empresa, é comum observar que as empresas familiares preservam objetivos não financeiros ou afetivos, definidos a partir de Gomez-Mejia et al. (2011) como riqueza socioemocional. Diversas abordagens buscam ajustar seus argumentos para o contexto de empresas familiares, no qual o modelo da riqueza socioemocional está intimamente ligado à 
realidade natural daquelas que optam por objetivos ligados aos valores da família, os quais podem mudar ao longo dos anos (Berrone et al., 2012).

Nesse contexto, a riqueza socioemocional proposta por Berrone et al. (2012) possui cinco dimensões qualificadas como FIBER: controle e influência familiar, identificação dos membros da família com a empresa, preservação dos laços sociais, apego emocional, e renovação dos laços por meio da sucessão dinástica. Esses elementos consistem em objetivos não econômicos que influenciam o processo de tomada de decisão nas empresas familiares (Berrone et al., 2012; Songini et al., 2013) e que tendem a criar barreiras para o seu processo de profissionalização (Kellermanns et al., 2012; Gomez-Mejia et al., 2011; Stewart \& Hitt, 2012).

Além disso, o conceito de profissionalização vem se desenvolvendo na pesquisa em contextos de empresas familiares, sendo vista como uma abordagem da dimensão da família no negócio, ou seja, o envolvimento da família na organização e a escolha de gestores não familiares, o que singulariza a profissionalização na gestão (Dekker et al., 2015; Stewart \& Hitt, 2012). Logo, há uma relevância entre o envolvimento de membros da família com outros profissionais na gestão da organização, inclusive por visões críticas distintas com o intuito de evidenciar o impacto da perpetuação de valores da família quanto a mudanças nos processos gerenciais, bem como para o crescimento da empresa.

Dito isso, parte-se do pressuposto de que as decisões estratégicas de empresas familiares são influenciadas por objetivos atrelados à preservação da riqueza socioemocional (Leitterstorf \& Rau, 2014). Apesar de grande parte da literatura sobre profissionalização no âmbito da contabilidade gerencial se apoiar em gestores que não pertencem à família, os quais são percebidos como principais percursores desse processo, essa é apenas uma visão unilateral (Hiebl \& Mayrleitner, 2019). Conquanto, nota-se que os objetivos da família controladora podem afetar o processo de profissionalização da empresa familiar (Hiebl \& Mayrleitner).

Stewart e Hitt (2012) argumentam que apesar de o conceito de profissionalização não ser bem-definido, a profissionalização também abrange, implícita ou explicitamente, o treinamento formal dos gestores, a meritocracia, a existência de estruturas e processos de gestão formalizados e/ou a atuação de gestores externos à família. Dekker et al. (2013) discutem empiricamente cinco dimensões sobre o nível de profissionalização em empresas familiares, quais sejam o uso de sistemas de controle financeiros, o envolvimento de executivos externos na governança, o uso de sistemas de controle de recursos humanos, a descentralização da autoridade e o envolvimento da alta administração.

No contexto brasileiro, estudos recentes têm trazido evidências empíricas acerca da profissionalização e adoção de mecanismos de contabilidade gerencial pelas empresas familiares. Oro e Lavarda (2019) evidenciaram que a gestão familiar e os valores oriundos da própria família contribuíram para a implementação da estratégia e o uso de medidas de 
desempenho. Hillen e Lavarda (2020), com o intuito de evidenciar como é vista a necessidade de orçamento nas empresas familiares que estão em processo de sucessão, acharam que pelas mudanças decorrentes do processo de sucessão que envolveu a profissionalização da gestão, por exemplo, houve um impacto na necessidade de um planejamento que levasse em consideração características de períodos de sucesso da organização. Buchweitz et al. (2019) observaram que o afastamento da família da gestão da empresa impactou negativamente na riqueza socioemocional, e isso comprometeu a continuidade da história da empresa, bem como a utilização da cultura para moldar as habilidades e competências para que a organização voltasse às atividades. Apesar dessas evidências, ainda não está claro como os valores e objetivos da família estão associados às dimensões de profissionalização da empresa familiar (Hiebl \& Mayrleitner, 2019). Nesse sentido, torna-se relevante a discussão da seguinte questão de pesquisa: como a riqueza socioemocional impacta no processo de profissionalização em uma empresa familiar? Dessa forma, a pesquisa tem por objetivo analisar como a riqueza socioemocional impacta no processo de profissionalização em uma empresa familiar de grande porte instalada em Santa Catarina.

Com o intuito de alcançar o objetivo proposto, analisaram-se as cinco dimensões da riqueza socioemocional propostas por Berrone et al. (2012) por este ser um modelo bastante difundido na literatura para investigar a riqueza socioemocional de uma empresa familiar. A profissionalização foi discutida a partir do constructo proposto por Dekker et al. (2013).

O estudo se justifica uma vez que, conforme Miller e Le Breton-Miller (2014), ao atrelar causa e efeito da riqueza socioemocional, destacam-se as motivações financeiras e as não financeiras, visto que as contribuições de uma empresa para a comunidade podem trazer retornos tanto financeiros quanto sociais. Além disso, por meio da profissionalização, a empresa familiar muda a forma de atuar e geralmente são afastados alguns líderes de cargos anteriores, com o intuito de alterar sistemas de apoio e implementar novas políticas e procedimentos; logo, a profissionalização pode impactar na cultura organizacional (Lisoni et al., 2010).

Quanto às contribuições do estudo, denota-se que há uma necessidade de evidenciar o impacto dos valores da família na gestão. Primeiro, grande parte dos estudos opta por demonstrar o conceito de profissionalização de forma mais simples, apoiando-se na vertente de que a contratação de executivos externos já consiste em um fator relevante e suficiente para que a empresa seja caracterizada como empresa familiar profissional (Dekker et al., 2015; Stewart \& Hitt, 2012).

Segundo, o estudo traz indícios sobre a associação entre as prioridades não financeiras e a profissionalização da empresa familiar, para a qual, conforme Buchweitz et al. (2019), a riqueza socioemocional deve ser levada em consideração, principalmente quando a empresa se encontra em transição para a profissionalização. Diante disso, diferentemente dos estudos que discutiram o efeito negativo da riqueza socioemocional sobre os elementos 
de profissionalização da empresa familiar (Kellermanns et al., 2012), o presente trabalho traz indícios sobre como a riqueza socioemocional impacta no processo de profissionalização.

Pretende-se, assim, conforme o objetivo do estudo, analisar como a riqueza socioemocional pode impactar no processo de profissionalização em empresas familiares, e que não apenas a inserção de especialistas que não pertencem à família podem iniciar a profissionalização de processos gerenciais dentro da empresa, trazendo como método a abordagem de um estudo de caso com subsídios para pesquisas que envolvam a riqueza socioemocional, visto que a temática ainda é um tanto embrionária nesse contexto (Kalm \& Gomez-Mejia, 2016; Hiebl \& Mayrleitner, 2019).

O trabalho está estruturado da seguinte maneira: a seção 2 discute a literatura relevante sobre empresa familiar, riqueza socioemocional e profissionalização. A seção 3 descreve os procedimentos metodológicos do estudo. A seção 4 apresenta a análise e discussão dos achados, e a seção 5 traz as considerações finais.

\section{REFERENCIAL TEÓRICO}

Nesta seção será apresentado o referencial teórico da temática do presente estudo, o qual aborda os conceitos utilizados para empresas familiares, especificamente a riqueza socioemocional. Na sequência, aborda-se a discussão da profissionalização em sua perspectiva multidimensional.

\subsection{EMPRESA FAMILIAR E RIQUEZA SOCIOEMOCIONAL}

As empresas familiares representam organizações que se destacam em vários setores da economia e contribuem inclusive em termos econômicos e sociais (Oliveira et al., 2012). Gomez-Mejia et al. (2011) apontam que a literatura sobre empresas familiares é pulverizada. Acredita-se que a busca por objetivos não financeiros pode capturar de uma melhor forma a particularidade das empresas familiares.

Assim, ao utilizarem a teoria da agência comportamental, Gomez-Mejia et al. (2007) argumentam que a riqueza socioemocional (SEW) se refere a aspectos não financeiros que atendem a necessidades afetivas da família, por conseguinte, o risco da riqueza socioemocional consiste em um ponto de referência para empresas familiares. Sendo assim, as empresas familiares tendem a não aceitar os riscos significativos sobre esses objetivos não financeiros. 
É destacado um conjunto de valores ligados a escolhas organizacionais, estratégias no processo de gestão, governança corporativa, dentre outros comportamentos que podem ser explicados por meio da riqueza socioemocional (Gomez-Mejia et al., 2011).

Nessa perspectiva, o modelo da SEW baseia-se em preceitos de estudos já realizados em empresas familiares, sendo que a essência está ligada à tradição comportamental da família. Em outras palavras, o modelo está intimamente ligado à dotação de que as empresas familiares são motivadas e comprometidas em preservar as práticas da riqueza socioemocional no que se refere a "dotações afetivas" (Berrone et al., 2012).

Também, ao se considerar o modelo de riqueza socioemocional, pode-se destacar pontos positivos e negativos quanto à utilização deste em empresas familiares no que se refere à tomada de decisão e a diferentes estratégias que poderão ser utilizadas dentro da empresa. Assim, ainda conforme Berrone et al. (2012), a riqueza socioemocional baseia-se em cinco dimensões, as quais se orientam por meio da preservação da riqueza socioemocional, em que os membros da família exercem o controle da empresa e também controlam e influenciam as decisões. Entretanto, apesar de serem considerados aspectos financeiros, ao se tratar da família na gestão da organização, as "dotações afetivas" são consideradas fortemente, independentemente de premissas financeiras. A seguir, apresentam-se as cinco dimensões da riqueza socioemocional conforme Berrone et al. (2011), as quais formam o modelo FIBER:

1. controle e influência familiar: o controle pode ser exercido pelo fundador ou pela coalizão dominante, sendo esse controle e a influência almejados por esses membros, em que basicamente as empresas familiares controlam e dominam os negócios da empresa, exercem autoridade e disseminam posição de propriedade na gestão da organização (Berrone et al., 2012);

2. identificação dos membros da família com a empresa: a empresa é vista como uma extensão da família, em que a identidade do fundador está altamente difundida de forma que se carreguem os preceitos e as tradições da família à empresa (Berrone et al., 2012);

3. laços sociais: essas empresas possuem laços com a comunidade em geral (fornecedores, clientes, funcionários), inclusive servindo como patrocinadora para eventos sociais. A empresa, por meio da influência e controle da família, em que a tradição e os valores da família são preservados na gestão da empresa, busca, por meio de ações com fornecedores e com a comunidade na qual está inserida, proporcionar eventos ou até mesmo ações para o bem-estar geral (Berrone et al., 2012);

4. apego emocional: emoções positivas ou negativas que circundam o âmbito familiar e o ambiente familiar. Nessa dimensão, o apego emocional pode servir como base 
para o entendimento da atuação de membros da família na organização, sendo que se pode, ainda por meio dessa dimensão, verificar pontos positivos quanto à gestão da família na organização, bem como se os membros da família se comportam de forma altruísta e o quanto comportamentos disfuncionais podem influenciar no controle da empresa (Berrone et al., 2012);

5. renovação dos laços familiares por meio da sucessão dinástica: intenção de transmitir o negócio para as futuras gerações, em que a empresa não representa apenas um bem em valoração, mas, sim, uma herança da família, ou seja, a empresa familiar é vista como uma tradição. Assim, visualiza-se o esforço para a continuidade da empresa e para a sucessão de novos membros da família no controle da empresa, também se busca a valorização da tradição da família no negócio, observando as dimensões citadas anteriormente (Berrone et al., 2012).

Nesse alinhamento, para Martínez-Romero e Rojo-Ramírez (2016), ao se referir à riqueza socioemocional, observa-se que o modelo é formado por um conjunto de sentimentos, relacionamentos, emoções e vínculos entre os membros da família, portanto é uma dotação proeminente nas empresas familiares. A preservação de questões ligadas à riqueza socioemocional pode inclusive determinar se a família envolve esforços para mudar o negócio para que alcance o sucesso ou a falência (Wilson et al., 2013). Somado a isso, observa-se que a riqueza socioemocional é um conjunto de benefícios ditos não financeiros e ligados ao bem-estar e ao atendimento às necessidades dos membros da família no que se refere às operações da empresa, e essa importância impacta na tomada de decisão e no comportamento da empresa (Gomez-mejia et al., 2011). Outros estudos recentes, como de Debicki et al. (2016), exploraram que a importância dada à riqueza socioemocional é um fator primordial para distinguir empresas familiares e não familiares, e os autores apontam três dimensões para testar tal importância: destaque da família, continuidade familiar e enriquecimento da família. Cabe destacar que essas dimensões estão alinhadas àquelas propostas por Berrone et al. (2012).

\subsection{PROFISSIONALIZAÇÃO}

Como um processo de transição que busca a formalização de processos e o auxílio na estrutura da organização tem-se a profissionalização. Conforme Stewart e Hitt (2012) sobre a gestão em empresas familiares, parte-se do pressuposto de que esta é gerida de maneira menos formal, racional e padronizada quando comparada a empresas não familiares.

Ademais, a profissionalização em empresas familiares exige atenção quanto a vários fatores que podem impactar na organização, como a estreita relação entre sócios, 
familiares e herdeiros. Os traços culturais da empresa, quando mal orientados, podem provocar problemas na hierarquia, na sucessão e na confiança entre os membros familiares, impactando negativamente no processo de profissionalização (Freitas \& Barth, 2011).

Nessa perspectiva, espera-se que empresas familiares busquem a profissionalização quando houver problemas de agência. A fim de resolver esses problemas, as empresas familiares podem implantar mecanismos para controlar os custos relacionados à agência, como sistemas de governança formais e sistemas de controle gerencial, e estimular o envolvimento de membros não familiares em diversas funções (Dekker et al., 2013).

Nesse contexto, Dekker et al. (2013) salientam que são necessárias dimensões de profissionalização para diferenciar as peculiaridades de empresas familiares. Esses autores propõem cinco dimensões da profissionalização: (i) sistemas de controle financeiros, que realizam avaliação do uso de orçamentos, avaliação de desempenho, bem como definição de metas e objetivos; (ii) envolvimento de gestores externos na estrutura de governança, em que se busca visualizar o envolvimento de membros não familiares na gestão; (iii) sistemas de controle de recursos humanos, vistos como sistemas de recrutamento, avaliação e recompensa; (iv) descentralização da autoridade, apontada como delegação de poder a gestores contratados; e ( $v$ ) atuação da alta direção, a qual evidencia a atuação do conselho e da área gerencial.

Lisoni et al. (2010) evidenciaram que durante a profissionalização a organização se adequou a processos mais formalizados, com regras e rotinas mais ligados aos objetivos da empresa. No processo de profissionalização houve uma maior atenção dispensada por uma parte da família quanto aos investimentos quando comparada à atenção dada às operações. Com relação à questão de investimentos, Buchweitz et al. (2019) observaram que a perda de vínculos estabelecidos na empresa familiar analisada foi mitigada com a concretização da sua venda a um grupo estrangeiro de investimentos.

Mais recentemente, Madison et al. (2018) examinaram especificamente o monitoramento dos funcionários familiares e não familiares na profissionalização do setor de recursos humanos $(\mathrm{RH})$. Os autores argumentam que quando há igualdade no monitoramento de membros não familiares e membros da família ocorre o fortalecimento na relação entre profissionalização e desempenho financeiro.

Depreende-se, portanto, que a inclusão de membros não familiares em contextos familiares demonstra benefícios quanto ao desempenho da organização, sendo a profissionalização vista como um fator positivo. Adicionalmente, ressalta-se que a compreensão de funções familiares nas organizações pode ser um indicativo de acesso dos indivíduos ao conjunto de recursos da família, além de contribuições dos próprios membros da família a ela mesma (Jaskiewicz \& Dyer, 2017). 


\section{PROCEDIMENTOS METODOLÓGICOS}

Este estudo caracteriza-se como exploratório, com abordagem qualitativa e realizado por meio de um estudo de caso. A metodologia qualitativa permite que a realidade empírica seja externa ao sujeito (Chua, 1986). O estudo de caso consiste em um pesquisador que avalia a característica marcante da cultura de um fenômeno, com a disponibilidade de acessar outras variáveis que possam ajudar na explicação desse fenômeno (Ahrens \& Chapman, 2006). Além disso, conforme Hiebl e Mayrleitner (2019), é de grande utilidade identificar características quanto ao processo de profissionalização da contabilidade em empresas familiares, o que pode ser examinado em estudos de caso.

Como instrumento de coleta de dados utilizou-se a entrevista em profundidade que, de acordo com Oliveira (1997), consiste em um entrevistador estabelecer contato com o entrevistado (por telefone ou pessoalmente). O levantamento dos dados foi realizado por meio de consulta ao site da empresa e de entrevista direta com o presidente e os diretores da empresa. Para a entrevista utilizou-se um roteiro semiestruturado baseado nos estudos de Berrone et al. (2012) e Dekker et al. (2013) com questões no sentido de analisar a preservação da riqueza socioemocional e a profissionalização de uma empresa familiar.

Para a análise dos dados utilizou-se a técnica de Análise do Discurso. De acordo com Howarth (2005), as diversas ferramentas de análise do discurso podem ser compreendidas como um conjunto de técnicas que possibilitam a compreensão e a explicação de fenômenos que já foram considerados significativos para a análise. A escolha dessa técnica permite a viabilização de elementos para a compreensão do fenômeno investigado (Berger \& Luckmann, 1991).

A análise do estudo foi realizada por meio da narrativa do caso (Czarniawska, 2000). Essa técnica consiste na seguinte estrutura: (i) informações pertinentes à organização captadas via entrevista com o presidente e os diretores da empresa; (ii) fragmentos do discurso, com a interpretação das entrevistas, análise de documentos e observações; e (iii) discussão entre os aspectos da literatura referente à riqueza socioemocional e à profissionalização e o encontrado no campo.

Nessa perspectiva, visando atender ao objetivo da pesquisa, primeiramente foram analisadas as cinco dimensões da riqueza socioemocional propostas por Berrone et al. (2012), em seguida, investigou-se o processo de profissionalização na empresa baseado nos estudos de Stewart e Hitt (2012) e Dekker et al. (2013). Por fim, analisou-se, em conjunto, como a preservação da riqueza socioemocional influencia a profissionalização na empresa familiar. 


\subsection{INTERAÇÃO ENTRE OS CONSTRUCTOS ANALISADOS}

Percebe-se que além da atenção dada ao envolvimento afetivo, os valores da família também tendem a ser vinculados à empresa. Ao se iniciar o processo de profissionalização, é relevante investigar como a riqueza socioemocional afeta esse processo, dado que o processo de profissionalização pode ser introduzido nas organizações a fim, por exemplo, de sanar problemas de agência decorrentes do altruísmo parental (Lubatkin et al., 2003) ou mesmo de garantir a competitividade do negócio.

A literatura tem proposto que a intenção da família em preservar sua riqueza socioemocional tende a inibir o processo de profissionalização da empresa familiar (GomezMejia et al., 2011; Kellermanns et al., 2012). Por exemplo, a fim de preservar o controle das decisões estratégicas da empresa, a família controladora não adotará mecanismos formais de metas e de avaliação de desempenho (Speckbacher \& Wentges, 2012; Songini et al., 2013) e manterá apenas membros da família na alta direção.

Ademais, a presença de membros familiares e de processos formais de gestão podem contrastar com um modelo que privilegia a preservação do controle familiar, do apego emocional e da identidade entre família e negócio (Miller \& Le Breton-Miller, 2014). Portanto, estudos anteriores têm debatido que a preservação da riqueza socioemocional e a profissionalização consistem em "objetivos" opostos.

Como o estudo concentrou-se em um estudo de caso, a empresa estudada é uma empresa familiar pertencente a uma holding familiar, está localizada em Santa Catarina e possui 50 anos de história e cerca de 1.200 funcionários. A empresa é uma S.A. de capital fechado que fabrica e comercializa isoladores elétricos para várias aplicações no mercado doméstico de distribuição de energia e linha industrial. A consolidação no mercado ocorreu por meio da modernização de processos, treinamentos e seleção rigorosa de matéria-prima, atendendo, dessa forma, às especificações técnicas exigidas pelas normas nacionais e internacionais e pelos clientes.

Além disso, em razão de a empresa estar passando pelo processo de profissionalização que vem ocorrendo na gestão nos últimos anos e que ainda não está finalizado, é possível inferir que há uma preocupação com a governança e os valores da organização, em suma, com a accountability da empresa, por meio da tradição e da importância tanto para a comunidade em que é localizada a sede da empresa quanto para o pequeno município.

Destaca-se, também, o fato de o proprietário da empresa estimular o processo de profissionalização visando principalmente à sustentabilidade da organização nesse mercado altamente competitivo. A Figura 1 apresenta o organograma da empresa com os cargos de gerência e diretoria. 
Figura 1

Organograma da empresa

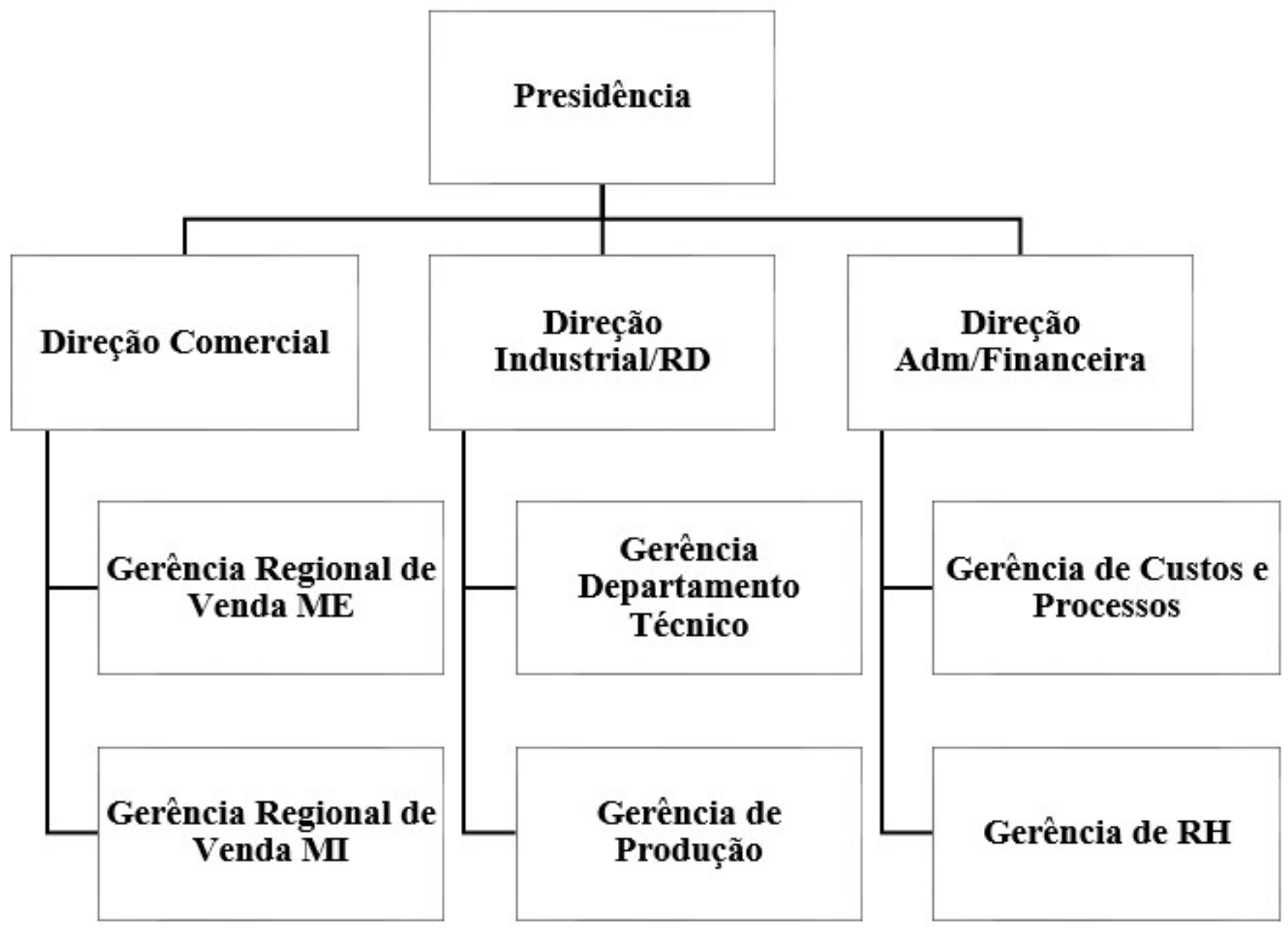

Para a amostra da pesquisa foram considerados: o presidente, o diretor comercial e o diretor industrial da empresa objeto deste estudo. Nesta amostra foram intencionalmente direcionados os principais gestores da empresa analisada, pois estão diretamente ligados com o controle e a influência da família, a identificação dos membros da família com a empresa, os laços vinculativos, o apego emocional e a renovação de laços familiares no processo sucessório, características presentes na riqueza socioemocional e que interferem no processo de profissionalização da organização. A Tabela 1 identifica os entrevistados na organização objeto de estudo:

Tabela 1

Identificação dos entrevistados

\begin{tabular}{ccccc}
\hline Cargo & Tempo de empresa & Duração $(\mathrm{min})$ & Data & Membro familiar \\
\hline Presidente & 30 anos & 60 & $02 / 03 / 2018$ & Sim \\
\hline Diretor comercial & 28 anos & 50 & $18 / 06 / 2018$ & Não \\
\hline Diretor industrial & 14 anos & 90 & $13 / 06 / 2018$ & Não \\
\hline
\end{tabular}


As entrevistas ocorreram no período de março a junho de 2018 por meio da visita dos pesquisadores à sede da empresa objeto de pesquisa. Seu tempo de duração variou entre 50 e 90 minutos, e elas foram transcritas e enviadas por e-mail aos sujeitos para que estes pudessem avaliar o conteúdo de suas respostas e se elas refletiam suas opiniões sobre os pontos abordados na entrevista. Essa prática foi estipulada no protocolo de ética do estudo acordado entre os pesquisadores e a empresa objeto de estudo/sujeitos da pesquisa.

Os entrevistados atuam na empresa há pelo menos 14 anos e ocupam cargos na alta administração. O presidente da organização é o único membro da atual gestão da empresa ligado à família e ao conselho de administração familiar, fazendo parte da segunda geração da família. O diretor comercial atua na empresa há cerca de 28 anos, iniciou sua trajetória na empresa atuando na produção e, após diversos cursos e treinamentos para especialização, tornou-se diretor comercial. $O$ diretor industrial faz parte da empresa há 14 anos e iniciou sua trajetória prestando serviço de consultoria para ela, após a conclusão do trabalho, ele foi convidado a fazer parte da diretoria na qual atua até hoje. Na seção a seguir são evidenciados os resultados encontrados neste estudo.

\section{ANÁLISE E DISCUSSÃO DOS RESULTADOS}

A empresa do estudo de caso é de origem familiar e é controlada pela segunda geração da família. Destaca-se que a gestão da empresa sempre foi conduzida por um membro da família. O presidente da empresa exerce forte influência na organização, e evidenciou-se, ainda, que outros membros familiares participam da gestão da empresa, especificamente na estrutura de governança de acionistas. A seguir demonstram-se os resultados obtidos a partir das entrevistas e os conceitos utilizados na estrutura desta pesquisa. A análise foi realizada de acordo com os tópicos da entrevista.

\subsection{RIQUEZA SOCIOEMOCIONAL}

A primeira dimensão da riqueza socioemocional refere-se ao controle e à influência familiar (Berrone et al., 2012). As entrevistas sugerem que a nomeação dos cargos de diretoria, bem como dos demais executivos da empresa é feita por meio de votação entre os sócios e os membros familiares nas reuniões do conselho de administração, e as pessoas são escolhidas de acordo com a sua competência técnica.

A captação pode ser realizada de forma interna ou externa, tendo em vista que em alguns casos houve a promoção da gerência para a diretoria $e$, em outros, consultores foram convidados a participar da diretoria. Importante destacar a esse respeito que Hiebl 
e Mayrleitner (2019) afirmam que a profissionalização de empresas familiares não pode ser evidenciada apenas por equiparar a profissionalização à presença de gerentes não familiares, mas também à descentralização das decisões e à adoção de mecanismos formais como a contabilidade gerencial (objetivos, metas, avaliação de desempenho).

Com relação à preservação do controle familiar e a interdependência da família no negócio, percebe-se que apenas o presidente, filho do fundador, atua diretamente na gestão da empresa. Além disso, diferentemente das empresas multinacionais, os diretores possuem certa autonomia para tomar algumas decisões, porém o presidente opina em aprovação à decisão ou não.

As entrevistas indicam que o elemento do controle e influência familiar é algo muito característico da empresa analisada, tendo em vista a estrutura de controle acionário, a composição da diretoria executiva e o estilo de gestão centralizado do presidente (membro da família). Levando em consideração o pensamento de Lisoni et al. (2010), o controle direto da família é evidenciado quando o principal executivo é membro da família e controla a organização.

Dessa forma, a preservação do controle e direcionamento dos planos estratégicos está centralizada na família e é mantida por meio da manutenção da cultura familiar disseminada na organização, como é observado pelo Diretor comercial:

Sentimos que o lado familiar busca manter, mesmo que profissionalizando a empresa, manter o lado humano. ... Em uma empresa multinacional você é meramente um número do crachá. ... E aqui não, porque as pessoas, as empresas são feitas de CPFs, e o CNPJ é apenas a construção. (comunicação pessoal, 18 de junho de 2018).

A segunda dimensão refere-se à identificação da família com a empresa (Berrone et al., 2012). Os valores da empresa e da família estão difundidos dentro da empresa e são os valores nos quais o proprietário acredita, confia e preserva e que são repassados a todos do corpo diretivo. Com relação à identificação dos clientes com o nome da família e os produtos oferecidos pela empresa, percebe-se que a marca da empresa é muito valorizada no segmento em que atua. Assim, conforme Buchweitz et al. (2019), por suas peculiaridades, empresas familiares apresentam uma aderência maior a um conjunto de características próprias da família perante o contexto empresarial.

Além disso, não há como dissociar um do outro, visto que os produtos carregam o nome da família. Conforme observado pelo Diretor industrial:

Você colocar o teu nome no produto, ele dá força, do que você inventar um nome fictício, porque você acaba não vinculando. Mas quando eles falam assim empresa $X$ ou empresa $Y$ ou a própria 
empresa Z eles dão valor porque eles sabem, eles relacionam, é daquela família, a família é séria, ou o contrário. O contrário também é verdadeiro, se é uma família "trambiqueira" e o nome está no produto, isso reflete no negócio também. Então no nosso negócio a marca $A B C$ é valorizada muito pelo nome, e ele é reconhecido no segmento, muito valorizado no segmento (comunicação pessoal, 13 de junho de 2018).

Os laços sociais fazem parte da terceira dimensão da riqueza socioemocional (Berrone et al., 2012). De acordo com os entrevistados, quando a empresa era regida pela primeira geração da família, o envolvimento da empresa na comunidade na qual está inserida era maior do que atualmente, tendo em vista que o proprietário adquiria vários terrenos e os vendia para os funcionários cobrando juros baixos e com condições de pagamento flexíveis, o que fez com que nos arredores da empresa fosse formada uma vila, a qual possui o mesmo nome da empresa. Entretanto, atualmente a empresa ainda promove diversas atividades, como patrocínios aos eventos e apoio ao esporte. Além disso, oferece assistência médica aos funcionários e seus familiares e tem uma cooperativa de crédito na qual a associação é feita de forma voluntária, com juros mais baixos para a utilização dos funcionários no caso de dificuldades financeiras, como se observa a seguir:

\footnotetext{
... O fundador, ele praticamente criou a vila aqui que surgiu porque ele comprava os terrenos que o funcionário não tinha condição de adquirir, então ele parcelava em 20 anos, 15 anos, e o funcionário ficava 15, 20 anos, era uma forma de reter a mão de obra que também era escassa na época, mas ao mesmo tempo era um benefício, porque ele abriu mão dessas propriedades todas. Já imaginou o valor de uma propriedade hoje aqui, é muito grande, hoje se tornou um bairro totalmente independente, o nome vila $[\mathrm{Y}]$, o pessoal tem tudo, tem a sua terra, a sua casa, e teve um grande valor nesse sentido, e nós também mantemos uma assistência social tanto com nosso funcionário, especialmente, como aos filhos e a família ... (Diretor industrial, comunicação pessoal, 13 de junho de 2018).
}

Conforme os entrevistados, os colaboradores são vistos como membros da família tanto pelo presidente quanto pelos demais diretores, os quais afirmam ter uma boa relação com os demais membros da família também. Entretanto, o Diretor comercial salienta que embora o relacionamento com os membros familiares seja bom, ele entende que um funcionário, apesar de se sentir acolhido pela família proprietária da empresa, precisa ter muito claras suas obrigações como empregado. Os dados da pesquisa indicam que a empresa atribui valor aos relacionamentos sociais, estando em linha com o que Berrone et al. (2012) discutem em termos de laços sociais, mas também fornecem indícios de que a empresa tem cada vez mais aderido práticas de profissionalização, como, por exemplo, estabelecendo que cargos de gestão devam seguir um perfil estritamente técnico. 
O apego emocional dos membros familiares ao negócio é tido como a quarta dimensão da riqueza socioemocional (Berrone et al., 2012). De acordo com os entrevistados, é difícil separar a emoção da razão, mas a racionalidade deve prevalecer para a continuidade do negócio. Para o presidente, a fim de evitar conflitos, possíveis cisões ou até mesmo a disputa de egos com os demais membros familiares, é preciso ter um argumento válido para sustentar o seu projeto, e os sócios podem acompanhar a evolução dele anualmente na assembleia geral na qual se apresentam todos os números, a evolução e a assertividade ou não do projeto, e a partir disso análise são tomadas importantes decisões.

Além disso, destaca-se que o bem-estar da família está diretamente ligado ao bemestar da empresa, tendo em vista que, para a continuidade do negócio, muitas vezes fez-se necessário que os familiares abrissem mão de parte do patrimônio particular para que o negócio se perpetuasse. Pode-se considerar que essa visão está de acordo com Gomez-Mejia et al. (2011), que enfatizam que a riqueza socioemocional é uma importante lente para interpretar o conjunto de escolhas estratégicas que empresas familiares adotam.

A última dimensão da riqueza socioemocional trata-se da renovação dos laços familiares por meio da sucessão (Berrone et al., 2012). A continuação do legado e a tradição da família é uma meta importante para a empresa, tendo em vista que a empresa expandiu ao longo das gerações, preservando os valores do fundador, como honestidade e transparência, por meio do trabalho com disciplina, qualidade, ética e respeito à tradição, que são valores e princípios pregados e perpetuados na organização.

Com relação ao processo sucessório, tem-se que ainda é uma incógnita para a empresa, considerando-se que os demais membros familiares não demonstraram interesse em participar da sua gestão futuramente. Desse modo, segundo o presidente, se esse processo acontecesse em curto prazo, a solução mais indicada seria nomear para a presidência um membro externo à família, mas que já faça parte da empresa.

A esse respeito, é importante ressaltar que a liderança pode ser transferida para um membro da família ou não, sendo que mesmo com a transferência a um não membro, a empresa continua sendo familiar, pois não há transferência especificamente de propriedade (Hillen \& Lavarda, 2019). O presidente ainda salienta que sua prioridade é a continuidade do negócio, mesmo que, para isso, sejam feitos alguns sacrifícios, mas sempre priorizando a manutenção dos empregos e o bem-estar dos funcionários, que são considerados como família.

\subsection{PROFISSIONALIZAÇÃO}

O constructo de profissionalização é composto por cinco dimensões (Dekker et al., 2013). A primeira refere-se aos Sistemas de Controle de Recursos Humanos, entendida como sistemas de recrutamento e avaliação de recompensa (Dekker et al., 2013). De acordo com 
o entrevistado l, passou a ser exigência da empresa a contratação de funcionários com as devidas competências técnicas, e não apenas por indicação, corroborando Stewart e Hitt (2012). Além disso, nesse ambiente de transição, uma das principais alterações ocorreu na elaboração do processo orçamentário, que é uma ferramenta utilizada para a avaliação de desempenho, como se observa nesta fala do Presidente: ". . a parte profissional é uma outra parte que você no sentido da palavra mais ou menos substitui a família por profissionais terceirizados, ela sendo familiar ou ela sendo profissional ela tem que ter números, tem que ter controle e orçamento." (comunicação pessoal, 2 de março de 2018).

A segunda dimensão refere-se ao envolvimento de gestores não familiares na estrutura de governança da empresa (Dekker et al., 2013). Como comentado pelos entrevistados, tanto - membro da família quanto os executivos contratados que compõem a diretoria executiva da empresa participam da elaboração do planejamento estratégico, que é um processo formalizado. Como a empresa objeto do estudo de caso é de capital fechado, conforme Hillen e Lavarda (2019), a governança da empresa familiar se refere mais a práticas que visam reduzir conflitos entre interesses da família e empresa.

Assim, após o consenso entre eles, o planejamento segue para aprovação dos demais sócios que participam da assembleia de acionistas. Nesse planejamento são definidas estratégias e metas de curto e longo prazo para manutenção e expansão do negócio válidas para três anos, sendo revisadas anualmente para o controle da evolução e possíveis alterações.

Prestação de contas bem-feita, bem-apresentada, junto com o plano estratégico também bemelaborado e consensado, não tem porque dar errado, então o que eu quero dizer, você tem que gastar bastante tempo no planejamento para o próximo ano, o próximo triênio e para os próximos cinco anos. Então a gente tem essa visão para os próximos cinco anos, então anualmente a gente revisa esse Planejamento. Se você faz esse planejamento, ele é apresentado para o Conselho de administração, primeiro para o presidente que participa da elaboração deste plano, depois este plano está pronto e é apresentado aos demais acionistas, estando todos de acordo, "beleza", vamos então para a prática ... (Diretor industrial, comunicação pessoal, 13 de junho de 2018).

Orçamento anual é elaborado primeiramente entre os diretores e os gerentes, sendo que, para os diretores, a participação dos gerentes é importante, pois eles identificam com maior amplitude as necessidades de determinados setores. As informações constantes no orçamento são minuciosas e úteis sobre cada departamento com o intuito de analisar as particularidades de cada um. É visível que a profissionalização é evidenciada por novos funcionários, tecnologias, sistemas de controle, planejamento e eficácia (Lisoni et al., 2010)

Posteriormente, realiza-se uma reunião com o presidente para discutir o orçamento. O acompanhamento é feito de forma mensal com reuniões formalizadas em ata, com data e 
horário marcados, e contam com o apoio de consultores externos para avaliar as implicações do orçamento no contexto macroeconômico, como aponta o Diretor comercial: "Alinhamos ele e mensalmente depois a gente acompanha o realizado com o orçado... e tomamos as devidas ações para o mês seguinte, e assim sucessivamente." (comunicação pessoal, 18 de junho de 2018).

Além disso, os entrevistados relataram que os controles financeiros, como o orçamento empresarial, são utilizados no dia a dia da empresa, em reuniões para discussão sobre o alcance das metas, cujas informações são utilizadas para a avaliação do desempenho e sistema de recompensas da alta administração.

Segundo o presidente, após a elaboração do orçamento as metas são rígidas e inflexíveis para alcançar o objetivo proposto. Deve-se considerar o que foi planejado, pois após a elaboração do orçamento ele não poderá ser modificado. Isso é interessante, pois, conforme Heinicke (2018), há uma inconsistência quanto ao impacto da profissionalização nos sistemas formais de controle com características que podem ser comparadas a grandes empresas. Nesse caso, é possível evidenciar que sim, há mais controles formais que se assemelham a grandes empresas.

Já para os diretores, após as reuniões de acompanhamento do orçamento trimestral e semestralmente, o orçamento pode ser modificado caso haja necessidade, porém essa alteração só pode ser realizada com a aprovação do presidente e do conselho de administração. Dessa forma, os diretores não possuem autonomia para modificá-lo. Nesse contexto, nota-se que a delegação de autoridade, que consiste na quarta dimensão de Dekker et al. (2013), é feita de forma parcial, pois os diretores possuem autoridade para algumas decisões, mas no que se refere a modificações de metas e objetivos, a autoridade centra-se nos membros da família.

Se você não insistir, se você por qualquer motivo, você tem que ser duro nisso, infelizmente não pode aceitar que não se atinja a meta, pode, por algum motivo, não chegar, mas aí no outro mês tem que puxar o que não conseguiu fazer no mês anterior. Se você não for rígido, é isso, é que nem uma aplicação de lei, se você matar alguém e não for preso, não for condenado, todo mundo vai matar, é uma coisa lógica, tem que ter, esse peso tem que ser muito grande, e claro você tem que ter uma equipe que tenha esse comportamento também, essa ambição de chegar nesses números e a vontade de chegar, de integração, tem muita coisa. Depois de planejado eles não mudam mais aquele ano (Presidente, comunicação pessoal, 2 de março de 2018).

Com relação à última dimensão da profissionalização, que avalia a atuação do conselho (Dekker et al., 2013), nota-se que não é tão evidente na empresa analisada, tendo em vista que as decisões gerenciais são centradas no conselho de administração formado por membros da família não atuantes no cotidiano da empresa, mas que são informados 
pelo presidente a respeito de assuntos pertinentes à administração. Entretanto, os diretores afirmam que caso haja necessidade, os demais membros podem solicitar informações quando desejarem, mas não é uma prática comum na empresa, conforme o Diretor industrial:

\footnotetext{
Eles têm liberdade de pedir, de virem, né, solicitar perante eles ali, - ó, queria ver como fechou mês passado - e tal, então, até porque somos uma S.A., os balanços são publicados, então ele nem precisa vir aqui, é só ele abrir o jornal e ver, abrir a internet e ver a publicação dos números, e ele vai ter lá, e se lá ele: - pô, mas eu não entendi isso aqui - , e quiser vir aqui, ele tem o direito, vamos dizer assim, claro que ele não vai vir aqui e vão perguntar lá para o cara da contabilidade, ele vai se dirigir a um diretor e pedir, ninguém abaixo da direção tem autonomia pra distribuir relatórios, entregar diagnósticos, né, algo desse gênero pra ninguém, né, não, só membro da família, pra ninguém. (comunicação pessoal, 13 de junho de 2018).
}

Portanto, apesar de o processo de profissionalização buscar limitar o envolvimento emocional da família nos negócios da empresa, nota-se que as decisões ainda são centralizadas no presidente e que este ainda exerce muita influência na disseminação do legado e tradição da família e da empresa. Além disso, a profissionalização permitiu padronizar e formalizar processos, bem como implementar mecanismos para aumentar a eficácia dos sistemas de controle gerencial e de governança.

\subsection{DISCUSSÃO}

Conforme apresentado, a riqueza socioemocional ainda influencia o processo de tomada de decisões na empresa familiar, em maior ou menor grau, com relação a cada uma das cinco dimensões discutidas anteriormente. Os valores e princípios da família se perpetuaram entre os funcionários e estão presentes no dia a dia da empresa. Por meio das entrevistas é possível perceber que a riqueza socioemocional não inibe o processo de profissionalização da empresa familiar. Pelo contrário, há indícios de que para alcançar os objetivos não financeiros expressos no construto da riqueza socioemocional, como, por exemplo, a continuidade do negócio, a riqueza socioemocional desempenha papel importante em todas as decisões (Gomez-Mejia et al., 2011). A organização tem adotado a estratégia de profissionalizar a sua gestão por meio da contratação de executivos externos e da implementação de sistemas de gestão de recursos humanos e financeiros, aspectos aderentes ao estudo de Deckker et al. (2013).

Além de auxiliar no alcance dos objetivos organizacionais, a contratação de gestores externos permitiu a diversificação estratégica da empresa, tendo em vista que a combinação de gestores não familiares com membros familiares forneceu diferentes perspectivas na 
elaboração do planejamento estratégico, mesmo que em última instância a aprovação seja da família. Isso evidencia uma contribuição para a governança corporativa da empresa, assim como discutido também por Eddleston et al. (2012). Assim, a inserção de membros não familiares em contextos familiares trouxe benefícios com relação ao desempenho da organização, e desse modo a profissionalização pode ser vista como um fator positivo (Jaskiewicz \& Dyer, 2017).

Ademais, percebe-se que a profissionalização foi natural dada a complexidade e as demandas da organização, e foi incentivada pela família para a manutenção dos empregos da comunidade local, a longevidade da empresa e a manutenção da reputação da empresa no mercado. Os membros não familiares participaram ativamente no processo de profissionalização e possuem uma relação de transparência com o presidente e único membro da família na organização. Desse modo, o apego emocional e os valores da família (Berrone et al., 2012) permaneceram mesmo após o processo de profissionalização.

Portanto, a profissionalização não provocou a perda da identidade familiar, apenas padronizou processos e permitiu aos gestores maior controle sobre a empresa. Além disso, a inserção de profissionais capacitados tecnicamente e não apenas por indicação, como no caso de muitas empresas familiares, permitiu maior criticidade e criatividade aos resultados encontrados, mas sem fazer com que a empresa perdesse seus valores, legado e tradição.

Dessa forma, verifica-se que a riqueza socioemocional influencia o processo de profissionalização, não no sentido de inibir o processo de profissionalização, mas de estabelecer os limites, timing e concessões que a família está ou não disposta a fazer com relação à inserção de membros não familiares em cargos diretivos da organização familiar. Conforme Oro e Lavarda (2019), em empresas familiares, no que tange ao processo de sucessão e de crescimento da empresa, mudanças na gestão podem ser evidenciadas, principalmente por esse tipo de empresa atuar com estratégias diferenciadas quando comparadas a empresas não familiares, e também pela cobrança de inovação na gestão. $E$ isso pode estar intimamente atrelado ao fato de que, conforme Buchweitz et al. (2019), os elementos da riqueza socioemocional são importantes para que uma empresa familiar seja gerida com sucesso.

Com base no exposto, a proposição que orientou o estudo foi $\left(P_{1}\right)$ : $A$ preservação da riqueza socioemocional reforça a profissionalização da empresa familiar.

\section{CONSIDERAÇÕES FINAIS}

O presente estudo objetivou investigar como a riqueza socioemocional impacta o processo de profissionalização em uma empresa familiar pertencente a um grupo de 
empresas localizado em Santa Catarina. Para tanto, realizou-se uma pesquisa exploratória, com abordagem qualitativa, e realizada por meio de um estudo de caso.

Constatou-se que o principal fator para a introdução do processo de profissionalização dentro da organização foi a sobrevivência em um ambiente altamente competitivo. Quanto à riqueza socioemocional na empresa pesquisada, infere-se que a família tem um papel ativo e diretivo em termos de controle e influência das decisões tanto em nível estratégico (aprovação via conselho de administração) quanto tático (o presidente é filho do fundador e está envolvido diretamente com a diretoria para aprovações e direcionamentos). Destaca-se, ainda, a importância atribuída à imagem do nome da família, aos relacionamentos sociais e ao desejo de manutenção do negócio familiar. Adicionalmente, percebe-se que os valores introduzidos pelo fundador ainda se perpetuam na empresa.

Diante da profissionalização, percebe-se que no contexto da organização objeto de estudo, foi uma forma de a empresa se "remodelar", mas sem perder seus princípios e identidade "familiares". Verificou-se que os membros não familiares que atuam na organização participaram ativamente no processo de profissionalização, até no que diz respeito à introdução de novos membros não familiares em suas equipes. Além disso, há uma transparência de relacionamento entre os diretores não familiares e o presidente, o qual é o único membro da família que atua diariamente na organização e é quem reporta as informações pertinentes à administração para os outros membros da família por meio das reuniões que ocorrem mensalmente na organização, permitindo que todos tenham conhecimento dos projetos, processos e atividades que a organização está executando.

Como resposta ao objetivo do presente estudo infere-se que os objetivos afetivos da família traduzidos em termos da riqueza socioemocional poderiam restringir/evitar a profissionalização da empresa familiar, não em termos apenas da contratação de gestores externos à família, mas também à adoção de mecanismos de contabilidade gerencial. Apesar de o tema profissionalização não ser tão recente no campo das empresas familiares, as discussões relacionadas ao interesse e aos objetivos da família como determinantes da profissionalização são ainda recentes na literatura (Hiebl \& Mayrleitner, 2019). Além disso, as evidências empíricas sobre profissionalização de empresas familiares ainda são recentes na literatura nacional (Buchweitz et al., 2019; Hillen \& Lavarda, 2020; Oro \& Lavarda, 2019).

Outrossim, a principal contribuição teórica do presente estudo consiste na ampliação do debate sobre as características da riqueza socioemocional e da profissionalização em âmbito nacional, por meio de um estudo de caso. Além disso, destaca-se o fato de que na organização analisada a profissionalização da gestão ocorreu de maneira benéfica, desmistificando-se o fato de que essa profissionalização faz com a empresa perca a sua essência familiar, sugerindo que esse processo não concorre com a preservação da riqueza socioemocional, o que vai contra os achados de Kellermanns et al. (2012), que evidenciaram em outro contexto o efeito negativo da riqueza socioemocional na profissionalização. Por 
outro lado, alinha-se às evidências de Buchweitz et al. (2019), que denotam que a riqueza socioemocional é um fator relevante para análise do comportamento de empresas que estão passando pelo processo de profissionalização.

A respeito das contribuições empíricas, cabe destacar que foi estudada uma empresa de grande porte, de capital fechado, que perpetua os valores da família na profissionalização e que almeja seu crescimento e longevidade. Apesar de o número de entrevistas ser limitado, elas foram realizadas com os sujeitos-chave da empresa: (i) único membro da família controladora envolvido na gestão do negócio, que é o presidente; (ii) dois executivos externos à família com tempo significativo de empresa.

Sugere-se, para futuras pesquisas, a investigação sobre se as prioridades com relação à riqueza socioemocional impactam diretamente em outras ferramentas de gestão na organização, como, por exemplo, o processo orçamentário, perante uma análise mais detalhada das mudanças decorrentes nessas ferramentas de gestão, como também a análise da exteriorização para novos conceitos, o que admite a utilização da investigação da riqueza socioemocional por um período de tempo na organização, levando em conta, ainda, o estágio em que a organização se encontra em relação ao ciclo de vida organizacional.

\section{REFERÊNCIAS}

Ahrens, T., \& Chapman, C. S. (2006). Doing qualitative field research in management accounting: Positioning data to contribute to theory. Accounting, organizations and society, 31(8), 819-841.

Berger, P., \& Luckmann, T. (1991). The social construction of reality: A treatise in the sociology of knowledge (10a ed.). Penguin.

Berrone, P., Cruz, C., \& Gomez-Mejia, L. R. (2012). Socioemotional wealth in family firms: Theoretical dimensions, assessment approaches, and agenda for future research. Family Business Review, 25(3), 258-279.

Buchweitz, M. J. R., Cruz, A. P. C., Barbosa, M. A. G., \& Pereira, T. A. (2019). A riqueza socioemocional e o declínio em uma empresa familiar: Um estudo da Guerra SA. RACE: Revista de Administração, Contabilidade e Economia, 18(2), 231-258.

Chua, W. F. (1986). Radical developments in accounting thought. Accounting review, 601632.

Czarniawska, B. (2000). The uses of narrative in organization research. GRI reports. 
Debicki, B. J., Kellermanns, F. W., Chrisman, J. J., Pearson, A. W., \& Spencer, B. A. (2016). Development of a socioemotional wealth importance (SEWi) scale for family firm research. Journal of Family Business Strategy, 7(1), 47-57.

Dekker, J. C., Lybaert, N., Steijvers, T., Depaire, B., \& Mercken, R. (2013). Family firm types based on the professionalization construct: Exploratory research. Family Business Review, 26(1), 81-99.

Dekker, J., Lybaert, N., Steijvers, T., \& Depaire, B. (2015). The effect of family business professionalization as a multidimensional construct on firm performance. Journal of Small Business Management, 53(2), 516-538.

Eddleston, K. A., Kellermanns, F. W., \& Zellweger, T. M. (2012). Exploring the entrepreneurial behavior of family firms: Does the stewardship perspective explain differences? Entrepreneurship Theory and Practice, 36(2), 347-367.

Freitas, E. C. D., \& Barth, M. (2011). Profissionalização da gestão nas empresas familiares: Estagnar ou inovar? Revista Brasileira de Gestão e Desenvolvimento Regional, 7(3).

Gomez-Mejia, L. R., Haynes, K. T., Núñez-Nickel, M., Jacobson, K. J., \& Moyano-Fuentes, J. (2007). Socioemotional wealth and business risks in family-controlled firms: Evidence from Spanish olive oil mills. Administrative science quarterly, 52(1), 106-137.

Gomez-Mejia, L. R., Cruz, C., Berrone, P., \& De Castro, J. (2011). The bind that ties: Socioemotional wealth preservation in family firms. Academy of Management Annals, 5(1), 653-707.

Heinicke, A. (2018). Performance measurement systems in small and medium-sized enterprises and family firms: A systematic literature review. Journal of Management Control, 28(4), 457-502.

Hiebl, M. R., \& Mayrleitner, B. (2019). Professionalization of management accounting in family firms: The impact of family members. Review of Managerial Science, 13(5), 1037 1068.

Hillen, C., \& Lavarda, C. E. F. (2020). Orçamento e ciclo de vida em empresas familiares em processo de sucessão. Revista Contabilidade \& Finanças, 31(83), 212-227.

Howarth, D. (2005). Applying discourse theory: the method of articulation. In D. Howard, \& J. Torfing. Discourse theory in European politics (pp. 316-349). Palgrave Macmillan. 
Jaskiewicz, P., \& Dyer, W. G. (2017). Addressing the elephant in the room: Disentangling family heterogeneity to advance family business research. Family Business Review, 30(2), $111-118$.

Kalm, M., \& Gomez-Mejia, L. R. (2016). Socioemotional wealth preservation in family firms. Revista de Administração, 51(4), 409-411.

Kellermanns, F. W., Eddleston, K. A., \& Zellweger, T. M. (2012). Extending the socioemotional wealth perspective: A look at the dark side. Entrepreneurship Theory and Practice, 36(6), $1175-1182$.

Leitterstorf, M. P., \& Rau, S. B. (2014). Socioemotional wealth and IPO underpricing of family firms. Strategic Management Journal, 35(5), 751-760.

Lisoni, J., Pereira, M. F., Almeida, M. I. R., \& Serra, F. R. (2010). Family Business: how family and ownership shapes business professionalization. Revista Brasileira de Gestao de Negócios, 12(37), 464-479.

Lubatkin, M. H., Simsek, Z., Ling, Y., \& Veiga, J. F. (2006). Ambidexterity and performance in small-to medium-sized firms: The pivotal role of top management team behavioral integration. Journal of management, 32(5), 646-672.

Madison, K., Daspit, J. J., Turner, K., \& Kellermanns, F. W. (2018). Family firm human resource practices: Investigating the effects of professionalization and bifurcation bias on performance. Journal of Business Research, 84, 327-336.

Martínez-Romero, M. J., \& Rojo-Ramírez, A. A. (2016). SEW: Looking for a definition and controversial issues. European Journal of Family Business, 6(1), 1-9.

Miller, D., \& Le Breton-Miller, I. (2014). Deconstructing socioemotional wealth. Entrepreneurship Theory and Practice, 38(4), 713-720.

Oliveira, S. L. D. (1997). Tratado de metodologia científica. Pioneira.

Oliveira, J. L., Albuquerque, A. L., \& Pereira, R. D. (2012). Governança, sucessão e profissionalização em uma empresa familiar: $(R e)$ arranjando o lugar da família multigeracional. Revista Brasileira de Gestão de Negócios, 14(43).

Oro, I. M., \& Lavarda, C. E. F. (2019). Interface dos sistemas de controle gerencial com a estratégia e medidas de desempenho em empresa familiar. Revista Contabilidade \& Finanças, 30(79), 14-27. 
Songini, L., Gnan, L., \& Malmi, T. (2013). The role and impact of accounting in family business. Journal of Family Business Strategy, 4(2), 71-83.

Speckbacher, G., \& Wentges, P. (2012). The impact of family control on the use of performance measures in strategic target setting and incentive compensation: $A$ research note. Management Accounting Research, 23(1), 34-46.

Stewart, A., \& Hitt, M. A. (2012). Why can't a family business be more like a nonfamily business? Modes of professionalization in family firms. Family Business Review, 25(1), 58-86.

Wilson, N., Wright, M., \& Scholes, L. (2013). Family business survival and the role of boards. Entrepreneurship Theory and Practice, 37(6), 1369-1389.

\section{Como citar este artigo:}

\section{ABNT}

AMES Alice Carolina et al. Preservação da riqueza socioemocional e a profissionalização em empresas familiares. RACE, Revista de Administração, Contabilidade e Economia, v. 19, n. 3, p. 1-24, set./dez. 2020. Disponível em: http://editora.unoesc.edu.br/index.php/race. Acesso em: dia/mês/ano.

\section{APA}

Ames, A. C., Nolli, J. G., Beck, F., Mucci, D. M. . (2020). Preservação da riqueza socioemocional e a profissionalização em empresas familiares. RACE, Revista de Administração, Contabilidade e Economia, 19(3), 1-24. http://editora.unoesc.edu.br/index.php/race 